Finisterra, XXXVII, 74, 2002, pp. 173-175

\title{
MODELAÇÃO GEOGRÁFICA DE INDICADORES DE DESENVOLVIMENTO SUSTENTÁVEL
}

\author{
Paulo Morgado ${ }^{1}$
}

As transformações provocadas na superfície terrestre, decorrentes das actividades humanas, têm aumentado consideravelmente quer no seu ritmo, quer na sua extensão. A dinâmica a que se têm vindo a processar essas transformações, frequentemente superiores à capacidade de análise e intervenção do Homem, é responsável por significativas situações de crise, provocadas por fortes pressões exercidas sobre o ambiente. Exemplo disso são, entre outros, os problemas das grandes cidades e das respectivas áreas metropolitanas, das áreas rurais e litorais, bem como das áreas de paisagem natural que ainda subsistem.

Os dirigentes políticos, a administração central, a administração periférica do Estado e muito particularmente os técnicos que têm responsabilidade sobre o território nos seus múltiplos aspectos, admitem a dificuldade em aferir e conjugar a quantidade enorme de dados com que são confrontados diariamente, considerando a multiplicidade de perspectivas pelas quais se pode abordar o território. Neste contexto, é cada vez mais premente a necessidade de sistematizar a informação para se determinar uma coordenação das diferentes acções, por forma a minorar os efeitos territoriais nefastos das intervenções isoladas. É para responder a estas necessidades que se utilizam os Sistemas de Informação Geográfica (SIG), sistemas capazes de estabelecer ligações entre as quantidades volumosas de elementos possíveis de integrar uma base de dados mediante a atribuição de coordenadas terrestres. Este facto permite visualizar, de forma dinâmica, o posicionamento geográfico, relativo e absoluto, de temas que têm sido discutidos de forma pouco integrada.

A complexidade que caracteriza a intensidade dos fenómenos inscritos na paisagem exige análise, diagnóstico e proposta interdisciplinares. Neste cenário, a Geografia assume uma posição privilegiada - conferida pelo seu próprio historial - enquanto ciência de charneira de conhecimentos e saberes, técnicos e científicos, com outras ciências (ciências naturais, ciências sociais e mesmo das ditas «ciências exactas»). Não obstante este legado científico e histórico, ou melhor ainda, por causa dele, a unicidade na Geografia apresenta carácter efémero, dando, não raras vezes, lugar a «uma 'depressão' existencial» (GASPAR,

1 Investigador do Centro de Estudos Geográficos e Assistente do Departamento de Geografia FLUL. E-mail: pms@mail.doc.fl.ul.pt 
1999: 3) e a consequentes crises de identidade. Os geógrafos ao introduzirem as Tecnologias de Informação Geográfica (TIG) como ferramenta de apoio à investigação científica introduziram também a necessidade de «recentrar» os procedimentos técnicos e os métodos de abordagem ao tratamento de dados espacialmente referenciados. Esta «inovação», ainda tímida, tem gerado alguma controvérsia. Nesta saudável controvérsia, aliás várias vezes repetida na história da Geografia tem-se reconhecido, em grande medida, que «Os testemunhos dos impulsos mais renovadores, e também mais controversos, estavam na teoria da Geografia e elaboração de modelos (os sistemas e geosistemas), na teledetecção e tratamento de dados (computação e informatização)... Só por si representam a "revolução da Geografia teorética e quantitativa» que, desde o final da II Guerra Mundial, tinha adquirido intensidade cada vez maior.» (AMARAL, 2001: 17).

Contudo, podem e devem emergir alguns consensos no pensamento geográfico e na prática da Geografia por forma a reafirmar a posição de destaque desta Ciência no estudo do Território, a diferentes escalas, e com linguagens alternativas baseadas na gramática dos mapas e dos modelos.

O desenvolvimento sustentável, o ordenamento e planeamento do território e os Sistemas de Informação Geográfica são a trilogia que compõe, estrutura e motiva a investigação que está na base da dissertação: «Modelação Geográfica de Indicadores de Desenvolvimento Sustentável» ${ }^{2}$, cujo objectivo principal consiste na quantificação e operacionalização de um conceito que tem tido uma componente quase que exclusivamente retórica.

A dissertação estrutura-se da seguinte forma: no primeiro capítulo aborda-se a questão do conceito de desenvolvimento sustentável que, apesar de ser frequentemente utilizado nos discursos políticos, não é empregue de forma cientificamente rigorosa. Assim, desenvolveu-se uma abordagem ao conceito numa perspectiva teórica, com o intuito de propor uma definição que esteja em consonância com os objectivos para os quais foi originariamente criado. Apontaram-se os valores éticos que devem enquadrar o conceito bem como os que são de natureza económica, social, ambiental e institucional. No segundo capítulo, defende-se a ideia de que o ordenamento do território é um dos instrumentos indispensáveis à concretização destas políticas, assim como das suas estratégias procedendo-se, para o efeito, ao estabelecimento dos objectivos e metas que devem ser atingidos pelas diversas figuras de plano.

O estado da situação, o seu prognóstico e as inflexões necessárias são realidades que só podem ser conhecidas, analisadas e porventura corrigidas, caso se disponha de indicadores adequados para cada um dos sistemas e subsistemas que caracterizam as actividades humanas, bem como para os territórios em que estas são exercidas. O terceiro capítulo é dedicado ao debate sobre os trabalhos realizados neste âmbito e à clarificação dos contornos do problema em si,

2 Dissertação de Mestrado apresentada e defendida no Instituto Superior Técnico, Universidade Técnica de Lisboa. Morgado, Paulo - Modelação Geográfica de Indicadores de Desenvolvimento Sustentável. Uma Aplicação à Área Metropolitana de Lisboa. Lisboa, IST/UTL, 2002, pp. 134. 
tentando responder a questões como: $\mathrm{O}$ que são os indicadores de desenvolvimento sustentável? Que estudos se têm realizado sobre esses indicadores? Como têm evoluído os critérios de escolha desses indicadores? Qual a finalidade dos indicadores de desenvolvimento sustentável? Como garantir a sua qualidade e a sua integridade enquanto informação geográfica? O quarto capítulo recupera a análise efectuada no capítulo anterior e revela os resultados apurados pela aplicação dos Indicadores de Desenvolvimento Sustentável a um caso de estudo: a área metropolitana de Lisboa. Deste modo, identificam-se indicadores capazes de definir o estado situacional, bem como o quadro futuro de um território, tendo por finalidade o prosseguimento do desenvolvimento sustentável.

Neste contexto, as variáveis em jogo são numerosas e a sua complexidade torna a sua manipulação muito difícil ou mesmo impossível, se não houver meios de recolha de dados e cálculos adequados. É neste ponto que surgem as Tecnologias de Informação Geográfica; não só para o tratamento dos dados alfanuméricos, mas também para a sua geo-referenciação e operacionalização. Por último, no quinto capítulo procede-se a uma breve revisão das capacidades e potencialidades tecnológicas disponíveis, no sentido de adquirir, armazenar, manipular e apresentar a informação recolhida, tendo por principal objectivo a identificação das ferramentas de análise espacial que os Sistemas de Informação Geográfica proporcionam.

Com o intuito de experimentar a metodologia concebida, o resultado final apresentado neste capítulo é o estabelecimento de um modelo geográfico que nos permite representar a realidade retratada pelos indicadores de sustentabilidade, que é aplicado ao território metropolitano de Lisboa. As Bases de Dados, os Sistemas de Informação Geográfica e a Detecção Remota são ferramentas indispensáveis para realizar tecnicamente este estudo. A articulação da análise supra-municipal com o cruzamento de informação está na base da criação do modelo. O propósito é o de mostrar possíveis cenários de e para o desenvolvi-

mento sustentável mediante a criação de uma interface gráfica que permite ao utilizador a escolha múltipla de informação geográfica a integrar no modelo proposto.

\section{BIBLIOGRAFIA}

Amaral, I. (2001) - Finisterra. Uma revista com 35 anos de prestígio científico. Finisterra Revista Portuguesa de Geografia, volume XXXVI (72). CEG, Lisboa: 11-25.

Morgado, P., (2002) - Modelação Geográfica de Indicadores de Desenvolvimento Sustentável. Uma Aplicação à Área Metropolitana de Lisboa. Dissertação de Mestrado apresentada e defendida no Instituto Superior Técnico, Universidade Técnica de Lisboa. Lisboa (polic.).

Gaspar, J. (1999) - Nós e os Outros. A Interdisciplinaridade na Geografia Portuguesa: Novos e Velhos Desafios. Inforgeo, Actas do III Congresso da Geografia Portuguesa, Porto, Setembro de 1997. Edições Colibri e A.P.G., Lisboa: 3-10. 